\title{
A co-designed heuristic guide for investigating the peace-sustainability nexus in the context of global change
}

\author{
Dahlia Simangan ${ }^{1,2}\left(\mathbb{D} \cdot\right.$ Hassan Virji ${ }^{1}$ Cullen Hendrix ${ }^{3} \cdot$ Moinul Islam $^{2} \cdot$ Shinji Kaneko ${ }^{1,2} \cdot$ Young-sam Ma $^{4}$. \\ Reinhard Mechler ${ }^{5} \cdot$ Prem Pangotra $^{6} \cdot$ Katie Peters $^{7} \cdot$ Ayyoob Sharifi, $^{1,2} \cdot$ Shamsul Hadi Shams ${ }^{8}$
}

Received: 14 July 2020 / Accepted: 27 April 2021 / Published online: 10 May 2021

(c) The Author(s), under exclusive licence to Springer Japan KK, part of Springer Nature 2021

\begin{abstract}
The interlinkages between peace and sustainability are embedded in several international agreements and declarations and recognized by various research studies. However, the characteristics of their bidirectional relationship remain underexamined. Here we scope the complex and multifaceted relationship between peace and sustainability based on an experts workshop held at Hiroshima University in August 2019. The workshop focused on how peace, as a process or a condition, can help or hinder sustainability and vice versa. Relevant environmental, socio-political, and economic and technological considerations highlighted at the workshop were integrated into a co-designed heuristic guide for investigating the peace-sustainability nexus in the context of global change. The proposed guide aims to assist academic and policy researchers in identifying the specific pathways through which peace and sustainability interact when addressing complex challenges. The reinforcing potential of the two will ultimately depend on the governance and management of global transformations.
\end{abstract}

Keywords Peace $\cdot$ Sustainability $\cdot$ Environment $\cdot$ Migration $\cdot$ Peace-sustainability nexus

\section{Introduction}

The intersection of peace and sustainability is not a new subject of academic inquiry. Earlier discussions on the linkages between peace, security, and the environment (e.g., Brock 1991; Mathews 1989; Myers 1989; UN 1992) prompted

Handled by Christian Pohl, ETH Zurich D-USYS TdLab

Universitätsstrasse, Switzerland.

Dahlia Simangan

simangan@hiroshima-u.ac.jp

1 Network for Education and Research on Peace and Sustainability (NERPS), Hiroshima University, 1-3-1 Kagamiyama, Higashi-Hiroshima, Hiroshima 739-0046, Japan

2 Graduate School of Humanities and Social Sciences, Hiroshima University, 1-5-1 Kagamiyama, Higashi-Hiroshima, Hiroshima 739-8529, Japan

3 Josef Korbel School of International Studies, University of Denver, Anna and John J. Sie International Relations Complex 2201 S. Gaylord St., Denver, CO 80208, USA

4 Jeju National University, (63247) Jeju-do Jeju-si Inda-1-gil 20 (Ara I-Park Apt.), Jeju City 105-804, South Korea further research on environmental security (e.g., Barnett 2001; Dalby 2002), environmental peacemaking or peacebuilding (Conca and Dabelko 2002; see also, Dresse et al. 2018), and ecological security (McDonald 2018). Integral to these discussions is the pursuit of peace and justice, especially in the context of global environmental change and the broader discourse on the Anthropocene (e.g., Chakrabarty 2012; Shue 2014; Simangan 2020), the proposed

5 Program Risk \& Resilience, International Institute for Applied Systems Analysis (IIASA), Schlossplatz 1, 2361 Laxernburg, Austria

6 Office of Academic Research, Hiroshima University, 1-3-1 Kagamiyama, Higashi-Hiroshima, Hiroshima 739-8511, Japan

7 Overseas Development Institute, 203 Blackfriars Road, London SE1 8NJ, UK

8 United Nations Institute for Training and Research (UNITAR), Hiroshima Office, 5th floor, 5-44 Motomachi Naka-ku, Hiroshima 730-0011, Japan 
geological epoch marking the planetary impact of human activities (Crutzen and Stoermer 2000). Cognizant of these developments, the study of peace and sustainability is starting to reflect the complexities of human societies and their interaction with the rest of the natural world. Similarly, the United Nations 2030 Agenda on the Sustainable Development Goals (SDGs) is an attempt to incorporate a multitude of objectives related to peace and sustainability and marshal a global, concerted plan of action towards a set of commonly agreed outcomes. As encapsulated in the Agenda, "there can be no sustainable development without peace and no peace without sustainable development" (UN 2015, p. 2). Indeed, peace and sustainability are two sides of the same coin, but how does peace impact sustainability and vice versa?

Despite recognition that peace and sustainability are interrelated, there is still limited knowledge on the nature of their relationship (Sharifi et al. 2021). Hence, we identify in this article the factors that need to be considered when examining the relationship between peace and sustainability amid global transformations. There is ample evidence that climate change, for instance, acts as a threat multiplier (Koubi 2019) that can exacerbate sources of conflict or prolong the duration of existing conflicts (e.g., Mach et al. 2019; Solomon et al. 2018). Climate change also has implications for how peacekeeping missions operate in conflict-affected societies (Born et al. 2019; Krampe 2019). On the other hand, war and conflicts can have lasting environmental, social, and economic impact. In fact, the first detonation of a nuclear weapon in 1945 during World War II is suggested to be the beginning of the Anthropocene (Zalasiewicz et al. 2015). More recently, the ongoing COVID-19 pandemic is also undermining peace and security in many parts of the world-from the erosion of trust in public institutions, disrupted provision of humanitarian needs, stalled peace negotiations and democratic processes, assault on human rights due to militarized and repressive lockdowns and curfews, and the rise of misinformation and divisive rhetoric (UN 2020). With peace and sustainability initiatives being undertaken from global to local levels and across sectors, understanding how peace influences sustainability and vice versa can help these initiatives draw on the sustainabilitypromoting potential of peace and peace-promoting potential of sustainability.

A better understanding of the complex relationship between peace and sustainability is, therefore, valuable amid global transformations. The literature on peace and sustainability articulates some aspects of the relationship between these two concepts. In peace studies, the field of environmental peacebuilding shifts away from the conflictcentered and deterministic environment-conflict discourses toward environmental conflict resolution and positive-sum interactions (e.g., Brock 1991; Conca and Dabelko 2002; Ide 2020). The concept of peace ecology, for instance, integrates perspectives from both peace and environmental studies to highlight the peacebuilding potential of the environment (Kyrou 2007). In sustainability studies, peace is considered as a precondition for sustainable development by promoting dialogue among multiple stakeholders on peace-centered sustainability approaches (Shrivastava and Suazo 2017). The concept of sustainability has also been articulated more broadly to include the resilience of social and ecological systems to manage crisis and change (Fisher and Rucki 2017). However, the specific characteristics of the relationship between peace and sustainability, such as their bidirectional linkages and the role of agency (i.e., those who dynamically shape the relationship), remain under-examined (Virji et al. 2019). Due to the broad connotations of peace and sustainability and their related concepts, previous research has typically investigated and measured the specific components of peace or sustainable development separately but not peace as a component of sustainability and vice versa.

To elucidate this inter-relationship, we propose a heuristic guide for identifying and explaining the different factors that influence the peace-sustainability nexus. Drawing on insights gathered from a two-day expert workshop organized by Hiroshima University in August 2019, we expound the environmental, socio-political, and economic and technological considerations in examining the relationship between peace and sustainability in the context of environmental changes, technological innovations, and urbanization. The workshop, titled Hiroshima Dialogue Forum on Peace-Sustainability Nexus, was organized by Hiroshima University's Network for Education and Research on Peace and Sustainability (NERPS). The Forum's objective was to engage with a diverse community of experts to consider the complex interactions at the intersection of peace and sustainability in the context of global change and global effort to achieve the SDGs, especially Goal 16 on "Peace, Justice, and Strong Institutions." The Forum enabled the identification of existing knowledge and knowledge gaps in explaining the relationship between peace and sustainability vis-à-vis the ongoing environmental, socio-political, and economic and technological transformations. The factors considered in these transformations are integrated into a co-designed heuristic guide for future academic and policy research into the linkages between peace and sustainability.

\section{Methodology}

To better understand the relationship between peace and sustainability, the Network for Education and Research on Peace and Sustainability (NERPS) at Hiroshima University held the first Hiroshima Dialogue Forum on the Sustainability-Peace Nexus in the Context of Global Change from 10 to 11 August 2019 at the Higashi-Hiroshima campus. The 
purpose of the workshop was to identify existing knowledge and knowledge gaps in explaining the relationship between peace and sustainability, particularly with environmental, socio-political, and economic and technological transformations as contextual backdrops. To do this, experts and practitioners from different countries, disciplines, and sectors were invited to engage in a structured deliberation on the following questions: (1) how can peace contribute to/detract from sustainability; (2) how can sustainability contribute to/detract from peace; and (3) what are the environmental, socio-political, and economic and technological drivers of the peace-sustainability nexus.

For 2 days, 32 participants from academia, national and subnational governmental agencies, non-governmental organizations, civil society, media industry, and private sectors unpacked the complex interactions surrounding the peace-sustainability nexus. The participants were largely based in Japan, but included others from Austria, China, the Philippines, South Korea, Thailand, the US, and the UK. Participants were invited to the Forum based on their expertise and published work and following recommendations from the organizing committee members and their networks. The academic disciplines of the participants ranged from sustainability science to urban planning, engineering, economics, peace and conflict studies, risk science, disaster and development studies, anthropology, international relations, and foreign policy. This diversity of disciplinary and professional backgrounds was crucial to examining the relationship between peace and sustainability both in theory and practice.

The workshop was organized into plenary sessions to set the thematic agenda and a smaller world café format for more in-depth discussions and cross-pollination of ideas as the participants moved between sessions (Brown and Isaacs 2005). On the first day, the participants were divided into two working groups, and each working group had two sessions to explore two pathways of the peace-sustainability nexus: (1) how can peace contribute to/detract from sustainability? And (2) how can sustainability contribute to/detract from peace? Each pathway had a dedicated chair and a rapporteur (Table 1). In those sessions, participants deliberated on the sources and pathways for peace fostering or hindering sustainability and vice versa. On the second day, the participants were divided into three working groups, and each

Table 1 General structure of the breakout sessions during the first day

$\begin{array}{ll}\text { Pathway 1 } & \text { Pathway 2 } \\ \text { How can peace contribute to/ } & \text { How can sustainability } \\ \text { detract from sustainability? } & \text { contribute to/detract from } \\ \text { (Chair 1 \& Rapporteur 1) } & \text { peace? } \\ & \text { (Chair 2 \& Rapporteur 2) }\end{array}$

\begin{tabular}{lll}
\hline Session 1 & Group 1 & Group 2 \\
Session 2 & Group 2 & Group 1 \\
\hline
\end{tabular}

working group had three sessions to discuss separately three overarching themes on the drivers of the peace-sustainability nexus: (1) environmental drivers, (2) socio-political drivers, and (3) economic and technological drivers. Each theme had a dedicated chair and a rapporteur (Table 2). The presentation of results in the following section is organized based on these thematic sessions. Relevant references to existing studies were also included to support some of these results.

The workshop was designed to encourage interactive dialogue among the participants and ensure their engagement with all the topics included in the sessions. The chairs posed a series of questions related to their assigned pathway or theme, and the participants (except for the chair and rapporteur) took turns in answering them. The participants were also invited to deliberate on their answers and pose related questions to the group. The groups employed visual mapping of their discussions during the workshop using whiteboards, markers, and Post-it Notes. A total of five chairpersons and five rapporteurs summarized and reported on the proceedings at the concluding session. In addition to the written reports, the activities during the workshop were documented using photo and video recording. This format generated expertly informed and intensively deliberated insights for analysis.

\section{Results}

We present in this section the workshop proceedings. The subsections are divided according to the questions deliberated in the workshop's sessions. The first subsection summarizes the answers to the questions posed during the first day of the workshop: how can peace contribute to/detract from sustainability, and how can sustainability contribute to/detract from peace? This discussion on the relationship between peace and sustainability is then further contextualized in the subsequent subsections. The three subsections are based on the sessions during the second day when the workshop participants (hereinafter referred to as "participants") discussed the environmental, socio-political, and economic

Table 2 General structure of the breakout sessions during the second day

\begin{tabular}{llll}
\hline & $\begin{array}{l}\text { Theme 1 } \\
\text { Environment } \\
\text { (Chair 1 \& Rap- } \\
\text { porteur 1) }\end{array}$ & $\begin{array}{l}\text { Theme 2 } \\
\text { Socio-politics } \\
\text { (Chair 2 \& Rap- } \\
\text { porteur 2) }\end{array}$ & $\begin{array}{l}\text { Theme 3 } \\
\text { Economy \& } \\
\text { technology } \\
\text { (Chair 3 \& } \\
\text { Rapporteur } \\
\text { 3) }\end{array}$ \\
\hline Session 1 & Group 1 & Group 2 & Group 3 \\
Session 2 & Group 2 & Group 3 & Group 1 \\
Session 3 & Group 3 & Group 1 & Group 2 \\
\hline
\end{tabular}


and technological drivers of the peace-sustainability nexus. We also added key references to relevant literature to support some of the insights from the workshop.

\section{Pathways of the peace-sustainability nexus}

Due to the broad connotations of peace and sustainability, the participants engaged in a debate about the terminologies of peace, sustainability, and conflict and the specific nature of their intersections. They conceptualized the terms in varying and, sometimes, even conflicting ways. For some, peace and conflict were defined by internationally agreed legal frameworks, whereas for others, the terms had broader connotations, including ideas such as conflicts of interest and process, which covers disputes over resource distribution, political representation, and equity central to sustainability transformations (Verweij and Thompson 2006). Similarly, some participants referred to the concept of sustainability specifically as the ambition to attain carbon-neutral pathways, while others expanded it to include social systems and the sustainability of socio-environmental systems. The lack of agreement among the participants initially posed an ontological challenge to moving the conversations forward. However, it also presented an epistemological opportunity to unpack the components of peace and sustainability and reconcile the conflicting inferences arising from them.

The workshop participants concluded that, while conflict inherently prevents the pursuit of sustainable action (i.e., conflict is inherent in sustainability debates and transformations and, unless managed well, prevents the pursuit of sustainability), peace does not necessarily lead to sustainability (i.e., peace is anecdotally a precursor to sustainability but offers no guarantees). One example highlighted during the discussion was Japan, an inherently peaceful society but one which still has some way to go in achieving its desired pathway to sustainability. Hence, the complexity of the relationship between peace and sustainability may not be an accurate or useful guide for understanding such a relationship in the future. Specifically, climate change will bring unprecedented change, and its uneven impacts will alter risk profiles and may result in new societal tensions and social conflict. In this context, the participants discussed how conflict might be inherent in any transition as implied, for example, by tensions arising from existing policy commitments related to the shift to low-carbon economies. From a peace perspective, the implications of sustainable development require further investigation. The participants deliberated these potentialities in relation to environmental, sociopolitical, and economic and technological considerations. The outcome of this deliberation led to the conclusion that the pursuit of sustainability can generate societal tension and reinforce existing conflict or facilitate peace formation. Participants thus suggested that due process, governance, and management of unintended consequences of environmental, socio-political, and economic and technological transformations are required to account for plural perspectives that may lead to consensus or compromise.

\section{Environmental considerations}

The participants identified several environmental drivers of peace and conflict when aiming for sustainability. In expounding on these drivers, they acknowledged that the move toward sustainable development might have different implications for rural and urban environments. The urban-rural divide could be reinforced if the benefits of sustainability-related initiatives are tilted in favour of one or the other. Urbanization is widely believed to be a driver of economic growth. Rapidly developing countries, most prominently China, invest in urban areas to maintain their competitive edge in the global economy (e.g., Lu and Chen 2006). Hence, politics and public policies in most societies are biased toward conferring benefits and services on urbanites, who are closer to the seats of power, face lower costs in mobilizing collectively, and who tend to include members of the upper and professional classes whose support is key to political stability and legitimacy. Relatedly, economics of scale incentivize more investment in urbanization; provision of public services is often less costly in more densely populated areas, making them much more likely to benefit from infrastructural improvements, including those related to sustainable food, water, and energy systems. At the same time, however, many international development agencies and organizations often view issues related to sustainable food and energy systems as rural issues, emphasizing rural interests and livelihoods in their programming. Tensions between urban and rural dwellers may erupt over spending on sustainability-related initiatives if these initiatives are seen as unduly favoring one constituency over the other. Hence, sustainability initiatives and their consequences for peace and conflict may look different for rural and urban environments.

The expert opinions of the participants coalesced around an agreement that sustainable development will require effective management of natural resources, particularly the co-management of crucial resources like the atmosphere, water, migratory fisheries, and other transboundary resources, as well as supply chains for associated goods and services. Better co-management of these resources for sustainable development will mostly augur peaceful outcomes as more equitable allocations of rights, responsibilities, and the creation of institutions for dispute resolution reduce incentives to resolve conflicts through force (e.g., Hønneland 2004; Krampe 2017). The process of negotiating better management schema can help create trust and build a basis for cooperation in other domains outside of the resource sector. 
However, there may be some unanticipated consequences of enhanced governance regimes. Efforts to combat climate change and better manage the atmosphere are already sparking political backlashes in heavily hydrocarbon-dependent countries, such as Australia, Canada, and France. These are coupled with the anticipation of high economic costs in the form of compensatory and technological transfers to Global South countries that feel the adverse effects of climate change but will have to forestall "dirty," carbon-intensive development schemes. Similarly, there may be conflict associated with perceived "meddling" by Global North countries in the Global South via mechanisms like these transfers and aid, which will-even if well-intentioned-lead logically to less policy autonomy for developing countries (Solà-Martín 2009; van der Velden 2018).

Thus, effective governance regimes and institutions may exclude some relevant actors. Far-ocean fishing of migratory populations, for example, is typically addressed through regional fisheries management organizations (Cullis-Suzuki and Pauly 2010). However, their ability to monitor and set catch targets or limits is curtailed when outside fleets operate in the fisheries and waters they govern. Similarly, agreements over water-sharing in river basins, such as the Nile basin, may be easier to achieve if some relevant stakeholders (i.e., basin countries that are not dependent on Nile waters or are the source of significant inflows) are excluded from participation. This, however, is counterintuitive to the notion that inclusive approaches are essential for achieving and sustaining peace. In each instance, there may be an efficiency vs. representation trade-off, resulting in conflict over access and usage rights.

Mitigating climate change and moving toward more sustainable energy systems will fundamentally change both the relative value of natural resources related to energy systems (post-legacy, carbon-intensive ones, and new, renewableintensive ones) and the nature of the political economies surrounding them. A more sustainable future will be powered by renewable, decarbonized energy sources, increasing the relative value of minerals associated with renewable energy generation and energy storage while likely decreasing that of hydrocarbons and their associated infrastructure. This revaluation is expected to have direct and indirect impacts on land use, linked to mitigation (through enhancement because of carbon sinks via reforestation) and the production of cleaner energy (e.g., biofuels).

The participants acknowledged that the transition to renewable energy is not likely to be seamless. Large deposits of many energy transition-related metals are located in regions already characterized by weak governance, endemic conflict, and unsustainable mining practices. In keeping with well-documented resource curse dynamics, these may exacerbate as demand and prices for these commodities increase. Paradoxically, the importance of these resources to energy transition will only increase profit-oriented motives associated with their exploitation.

De-carbonizing the energy system poses clear challenges for economies that revolve around carbon-intensive energy exports, such as oil and natural gas. Carbon emissions reductions will be a necessary component of any climate change mitigation protocol. Although emissions cuts will entail costs for all economies, they will be greater for energyintensive economies and hydrocarbon-producing countries. Countries like Saudi Arabia and other members of the Gulf Cooperation Council will be particularly vulnerable. These changes will have serious political and security ramifications. For instance, destabilizing dynamics in global energy markets, such as the 2019 attacks on oil refineries in Saudi Arabia, have renewed calls for moving from fossil fuels dependence to energy independence policies in the United States. As this trajectory for renewables accelerates the trend toward the obsolescence of conventional energy sources, elections in these regions may increasingly revolve around attempts to stymie this transition (Aklin 2018; Cheung and Davies 2017). More generally, conflict may emerge between those regions and local economies buoyed by the renewable energy transition and those left behind by said transition.

During the workshop, several prospects for increased cooperation and peaceful outcomes were identified despite the political and economic consequences of environmental sustainability. If appropriately managed, investments in renewable energy technology may bring needed economic and institutional development to impoverished regions (e.g., Karekezi 2002), increasing prospects for peace. Reduced demand and, therefore, prices, for hydrocarbons will temper the bellicose stances of energy exporters in international affairs, making their relations with neighbors relatively more peaceful. Furthermore, advanced technologies can further reduce the cost of producing renewable energy, eventually making it economically advantageous. Finally, de-carbonizing the energy system will pay large dividends in terms of better public health outcomes, especially in currently coalintensive energy economies, considering that poor public services and infrastructures undermine human security and are usually a source of the types of grievances that fuel political instability (Hegre et al. 2016).

Figure 1 summarizes the working groups' discussion on the existing knowledge and knowledge gaps pertaining to the environment when examining the relationship between peace and sustainability.

\section{Socio-political considerations}

Political instability and social unrest are inevitable in any transformation, especially when it is poorly managed. The participants agreed that institutions embedded in existing socio-political systems play crucial roles in promoting peace 


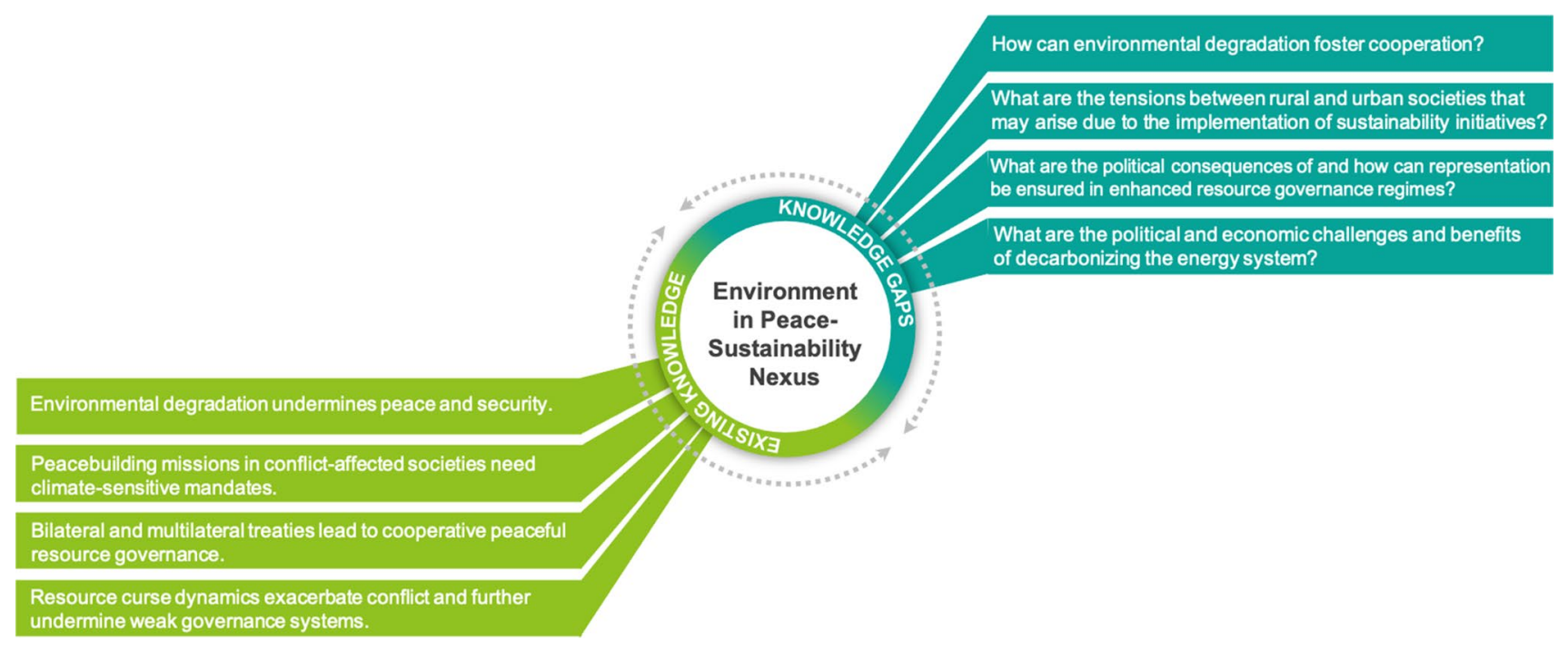

Fig. 1 The environment in the peace-sustainability nexus

and sustainability or reinforcing conflict and unsustainable practices. While acknowledging that institutions influence the peace-sustainability nexus, the participants reflected on the degree and reach of this influence in various socio-political contexts, including institutional characteristics, governance arrangements, and development objectives under which institutions operate.

The participants understood that institutions could be categorized according to type (e.g., government, non-governmental organization, youth, media, religion, academia, and business), their level of operation (e.g., international, national, subnational, and local or community grassroots), and the dynamics and directions of their interactions (e.g., cooperation, co-option, resistance, and conflict). Several factors frame the ability and willingness of institutions to advance peace and sustainability, and some of these were identified during the workshop. First, public support, or the lack thereof, that is sometimes translated into social movements, can hasten or hinder decision-making processes and the implementation of policies related to peace and sustainability (Jackson and Curry 2004; Parsons 2011; Pomeroy et al. 2007). Second, communitybased organizations can also complement the initiatives of formal and state-based institutions (Pomeroy et al. 2007; Sharma et al. 2007). Initiatives at the local level, such as the SDG Future Cities launched by the Japanese government and participated in by various stakeholders in Japan, can be considered more effective at distilling the values and practices of peace and sustainability. With a better understanding of local culture and traditions, these initiatives have the potential to encourage local involvement and local ownership. However, in some cases, the challenges are too complex and the required responses are too costly for these organizations to act commensurately. Third, government institutions can tap into the potential of private institutions in aligning with peace and sustainability goals by making them understand the benefits of long-term risk management and social-impact investments over short-term profit-oriented business models. In Yokohama, Japan, for example, the co-creation of a living lab or open innovation network is run by the private sector and participated in by different stakeholders, generating user-oriented solutions to local issues. Businesses might be willing to fund innovative and practical data collection through corporate philanthropy if dividends are emphasized in funding proposals.

To identify the socio-political drivers of the peace-sustainability nexus, the participants found it useful to examine the operationalization of the SDGs, particularly Goal 16 , which aims to promote peaceful and inclusive societies for sustainable development, provide access to justice for all, and build effective, accountable, and inclusive institutions at all levels. Notwithstanding the challenges and dilemmas surrounding its implementation (e.g., Zuber 2016), Goal 16 resonates with the question of how socio-political systems could reinforce or undermine the peace-sustainability nexus depending on different factors. For example, the understanding and operationalization of Goal 16 may vary across scales, from the national level to the local level, potentially leading to misunderstanding or tension between institutions and agencies and their intended actions and results. Grassroots-level organizations that are working more closely with local communities are likely to have a different interpretation and implementation approach to the SDGs compared to national governments, which are more focused on international agreements and top-down policies. 
Examining the gaps, complementarities, inconsistencies, and even tensions between national and local interpretation and operationalization of the SDGs is necessary for pursuing coherent approaches towards commonly defined peace and sustainability outcomes.

Socio-political systems also vary depending on national contexts, which can then influence how countries adopt and implement the global agenda on peace and sustainability. Although developing countries expect as much from the SDGs as developed countries, they usually have a lesser capacity to fulfill the goals due to different risk profiles, governance arrangements, and economic trajectories. Many developing countries are contending with issues of corruption, thereby hindering democratic practices, such as public accountability and access to reliable information. Relatedly, in the age of rapid technological advancement and instantaneous communication, the participants recognized the importance of internet connectivity and the right to information. The deterioration of access to free and independent information as well as the recently increasing restrictions on press freedom and internet access, undermines peace (Institute for Economics \& Peace 2018). In India, for instance, the passing of the Right to Information Act in 2005 has exposed numerous forms of corruption and paved the way for identifying the primary sources of corruption and proposing policies to combat them (Roberts 2010; Surie 2011).

The relevance of socio-political systems in the promotion of peace and sustainability may also change in an emergency or disaster context. On the one hand, environmental disasters challenge the effectiveness of socio-political institutions, exposing insufficient capacity and capability in disaster risk governance, leading to conflictual or peaceful outcomes (Peters 2019). In societies with non-functioning or ineffective institutions, the impact of disasters on the population can be exacerbated (Koubi 2019; Peters 2019). Disrupted states (often labelled as "fragile" or "weak" states) are also typically less capable of delivering basic services and addressing challenges to peace and sustainability. In many cases, scaling up capacity for institutions to cope with changing climate and hazard risks competes with other demands, such as economic growth or stability and security. On the other hand, environmental disasters have the potential to bring about cooperation and institutional reform relating to disaster risk management, climate change adaptation, mitigation, and peacebuilding, for example (Peters 2019). How to encourage and maximize this potential still needs further study.

The participants identified several recommendations for how socio-political systems could maximize their effectiveness in bridging peace and sustainability goals. First, top-down and bottom-up approaches must be initiated by socio-political institutions and strategically combined to fill the gap in policy implementation. Participation in sustainability initiatives by local communities needs to be encouraged by providing them with economic incentives to garner public support and avert social unrest. The localization of SDGs, in particular, can contribute to ensuring the long-term relevance and effectiveness of policies on sustainability (e.g., Morita et al. 2020; Okitasari 2019) and peace across societies and generations.

Second, governments have different approaches to addressing issues surrounding peace and sustainability. However, it is vital for governments to provide options to various stakeholders for opting into the SDGs and to highlight the cost-benefit structures of attaining them. Therefore, participatory decision-making processes may bolster the distillation of information between national governments and subnational and local stakeholders. Democratic processes enable affordable access and unobstructed flows of information (Hollyer et al. 2011), which are imperative for raising awareness about urgent issues and encouraging problem-solving deliberation.

Third, for socio-political systems to effectively pursue peace and sustainability, they need to maintain the basic mechanisms for functioning institutions. Conditions of political instability, including a lack of sustainability in policies in the cases of governmental changes, conflict, and disasters, may undermine the operation and legitimacy of these institutions, making them less effective at equally addressing issues of peace and sustainability. In the Philippines, for instance, the national government established a dedicated agency, the National Resilience Council, that is independent of political transitions in the country and with its vision anchored on the SDGs.

Fourth, the political will of relevant actors and maintaining the ethics and credibility of socio-political institutions have a significant influence on preserving peace and sustainability. In this case, the media should maintain independence and credibility in disseminating information to the public because they can shape social dynamics and political directions (Baum and Potter 2008). In Japan, for example, although a wide range of media agencies already provide diverse views to the public, there is still room for a more balanced view of information pertinent to the environment, such as energy policy, to enable the public to understand the issues and make informed decisions.

Fifth, cooperation between state and non-state actors must be enhanced for joint implementation of the SDGs. This partnership can be cultivated through building the capacity of NGOs and by allowing them to exercise some degree of autonomy from financial donors and government authorities when implementing the SDGs at the local level. NGOs will then be incentivized to move beyond project monitoring and focus more on collaborative work with their partner communities. Societal, political, economic, and cultural factors in societies/countries configure the 
characteristics, processes, and dynamics of socio-political transformations. Therefore, the participants raised caution about endorsing blanket approaches that are insensitive or irrelevant to local contexts.

Figure 2 summarizes the working groups' discussion on the existing knowledge and knowledge gaps pertaining to socio-political systems and institutions when examining the relationship between peace and sustainability.

\section{Economic and technological considerations}

Economic imperatives and technological innovations have implications for the pursuit of peace and sustainability. In addition to the economic and social consequences of sustainability initiatives discussed in the previous sections, this section deals with economic considerations in the context of rapid technological innovation. The participants identified both the prospects and dangers of technology in either managing or further destabilizing peaceful or disruptive economic and social transformations brought about by global environmental change.

The unprecedented proliferation of the digital opens up diverging scenarios, including what concerns the peace-sustainability nexus. Infrastructural improvements in technology, as translated in smartphones, the Internet, and big data, among other technological innovations, are transforming human lifestyles and interactions (Bettini et al. 2020). In some cases, how security threats are interpreted and addressed depends on algorithms and big data (Aradau and Blanke 2017). These technologies have also created new economic sectors and dynamics in capital accumulation.
Indeed, the shift toward digital technologies and algorithms has made the digital sector an important source of capital accumulation (Bettini et al. 2020; see Srnicek 2017 for the concept of 'platform capitalism').

Notably, the digital entails more than just machines and bits or infrastructure. Big data analytics, artificial intelligence, and algorithms are opening up new modes of governance (Bettini et al. 2020). In particular, pre-emptive security practices drawn from big data and operated by self-learning algorithms raise political and ethical dilemmas (Bettini et al. 2020). Additionally, many dual-use technologies (such as nuclear and bio-medical) could pose serious threats to human life while producing enormous economic benefits. Space technologies, on the other hand, contribute positively to improving earth observation and energy efficiency. Hence, the workshop participants emphasized the need to identify, disseminate, and address the ethical dilemmas of such technologies to avoid doing more harm than good.

The rise of the digital is disrupting established modalities of environmental governance (Bettini et al. 2020). Improved mapping and sensing are transforming various sectors, such as conservation and waste reduction, and contributing to the fulfillment of SDGs (Anderson et al. 2017; Arts et al. 2015; Koomey et al. 2013). With these considerations, the participants concurred with the general observation that emerging technologies in many fields present both opportunities and threats to the labour force that are likely to vary across countries. One of the major challenges during future technological transitions would be to identify segments that would be most vulnerable to job losses. Another challenge would be inequalities of access that may result in an unequal distribution of economic benefits and costs, thereby increasing

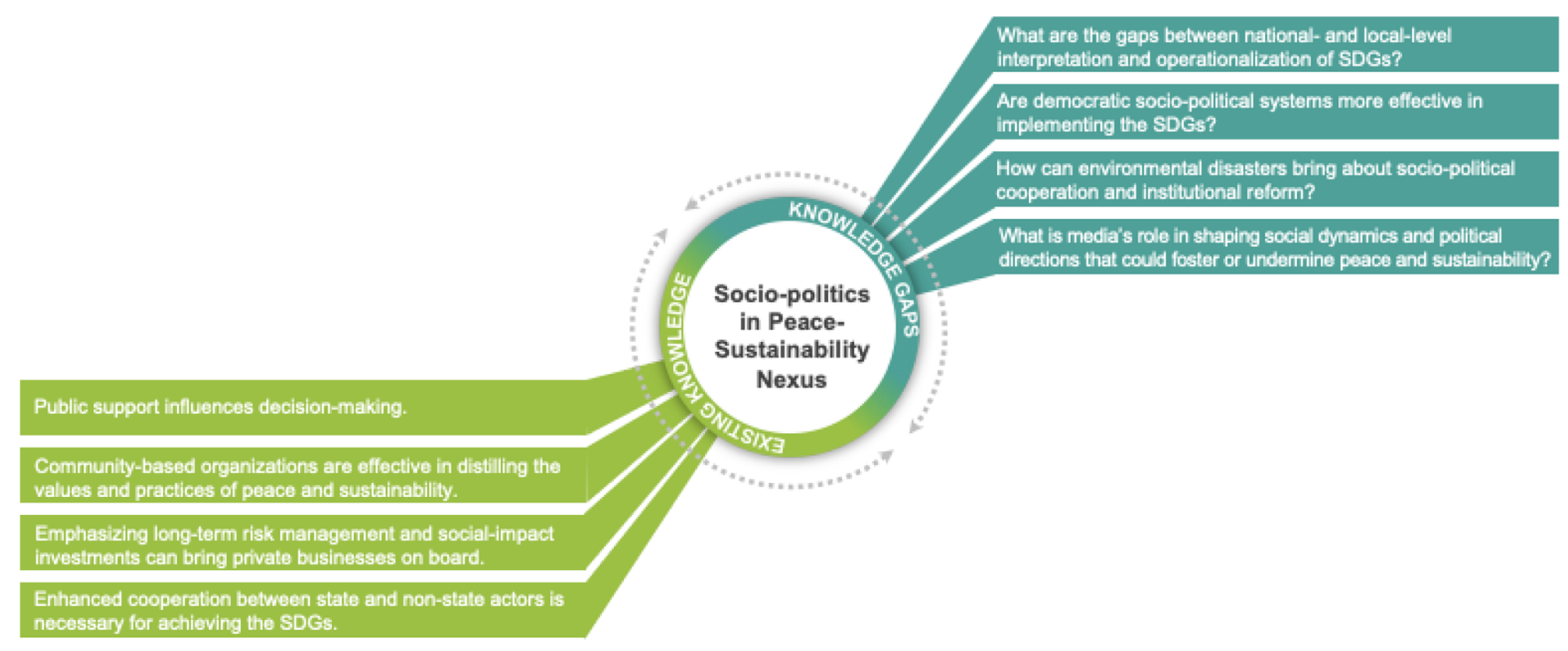

Note: This figure is illustrative of the working groups' discussion and, therefore, not exhaustive.

Fig. 2 Socio-politics in the peace-sustainability nexus 
social division and tension. For instance, the environmental costs of many technologies are disproportionately borne by economically disadvantaged groups, while privileged groups can appropriate a disproportionate share of the benefits of technologies. This has been the case with the rapid adoption of information and communications technology (ICT) and digital technologies in e-commerce, social media, and business process outsourcing in recent years (van der Velden 2018).

The inaccessibility of digital technologies and resources also poses a challenge to people living in conflict-prone areas in terms of resolving conflict and fostering cooperation. The role of state actors in mediating, moderating, and resolving conflicts while ensuring fair or equal access to technologies and providing capacity-building through education and training will be crucial in mitigating the unintended socio-economic inequalities resulting from technological advancement. In particular, the participants suggested the following measures to mitigate these negative consequences: (1) continuing education and retraining of workers through partnerships between governments and private sector, (2) reforming the education system by interfacing with industry and placing greater emphasis on data sciences, logical thinking, and programming concepts in schools, and (3) striking a balance between the decentralization of work and the demands of jobs, better matching of the workforce with job profiles, and creating safety nets to protect the most vulnerable sectors of society.

The participants understood that while advanced technology applications hold enormous promise for improving human welfare, certain technologies could also pose huge risks. Many participants raised concerns about the sharing compromising the privacy of individuals. The discussion on Society 5.0 (Shiroishi et al. 2018), a Japan-based vision document and roadmap for future technological development, revealed the existing challenges at the interface of technology and the economy. Better regulations, stakeholder involvement, and international agreements on boundaries for sharing personal data were some of the solutions identified during the workshop.

The outcomes of economic and technological transformations are yet to be seen, and it is not unlikely that a series of tendencies will deploy in parallel or conflict with each other. In anticipation of these tendencies, the participants raised several questions about economic and technological considerations when examining the peace-sustainability nexus. How will the digital affect labour markets and relations, and with what impacts on different social groups? Relatedly, how can the digital lead to more efficient and transparent processes, rather than draconian control and faster, more fragmented exploitative relations? How can the huge infrastructural impacts of the digital on the environment be mitigated and distributed fairly? With these questions, the participants agreed on the importance of ensuring that the "digital turn" will foster pathways of development, combining more sustainable practices and cohesive, peaceful communities (locally, nationally, internationally). Reflexive, accountable, and evidence-based approaches are required for exploring and addressing the many issues regarding technology, not least the ethical (e.g., del Rio et al. 2016; Kosmerlj et al. 2006), with consideration of the externalities and distribution that such infrastructural and cultural transition entails.

Figure 3 summarizes the working groups' discussion on

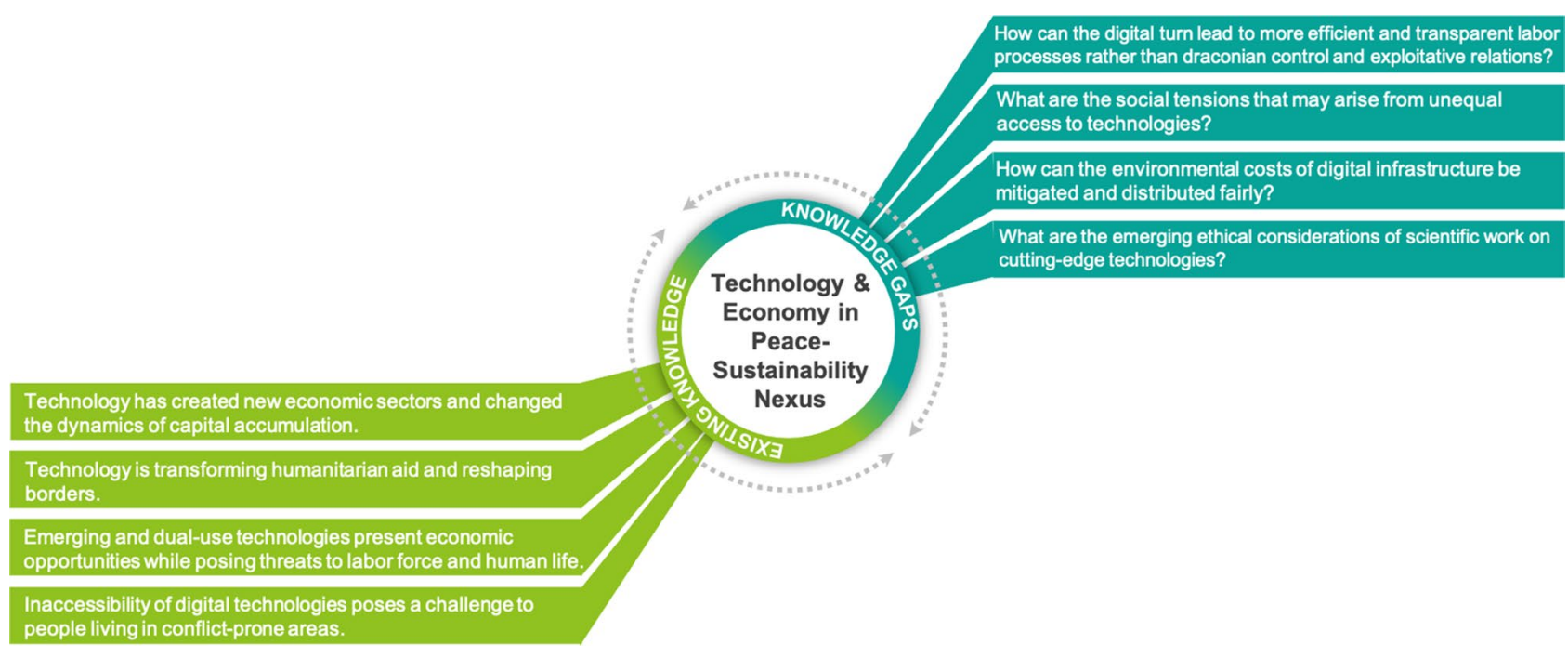

Fig. 3 Technology and the economy in the peace-sustainability nexus 
technology and the economy when examining the relationship between peace and sustainability.

\section{Discussion}

The deliberations during the workshop confirm that the relationship between peace and sustainability is indeed complex, bidirectional and, given their broad conceptualizations, driven by myriad factors. Although peace and sustainability are inextricably linked, empirical evidence of their causal relationship is yet to be established. However, a consensus emerged among the participants that the governance and management of environmental, socio-political, and economic and technological transformations ultimately determine the relationship between peace and sustainability. The management of these transformations may include not just addressing what already exists but also, if necessary, undoing, mitigating, and altering the conditions that have led to the unsustainable and conflict-reinforcing manifestations of these transformations. The discussion during the workshop can be summarized into a heuristic guide (see Fig. 4) aimed at directing future research toward projects that enhance the management of these transformations, in addition to initiatives focusing on the outcomes of the specific components of such transformations. The proposed guide also aims to inform future academic and policy research of the considerations when managing these transformations and identifying the specific pathways through which peace and sustainability interact. Examples of the considerations that were raised during the workshop are also listed in Fig. 4.

Research on the overlapping environmental, socio-political, and economic and technological considerations of peace and sustainability goals requires a transdisciplinary epistemology and methodology across multiple scales and in collaboration with experts and stakeholders from different countries and sectors. One method is deep immersion into relevant case-study contexts, policy exercises, and living labs to combine participatory methods with expert-based analytical tools and modelling. Another form of immersion is citizen science, which builds on the wisdom of crowdsourcing, particularly by incorporating and empowering the voice of the poor reporting from the frontlines of climate change and other global transformations. Employing inductive participatory research approaches allows the incorporation of local perspectives into the design and implementation of research initiatives. These approaches will narrow the gap between researchers/practitioners' perspectives and local needs and aspirations by prioritizing the risks identified by those immediately and disproportionately affected by conflict and environmental change. As recognized during the workshop, it is also essential for research outputs to be disseminated not just to academic circles but, more importantly, also to policymakers, the private sector, media, community-based organizations, and ordinary people. Hence, the participants recommended future research initiatives that are transdisciplinary in scope, design, participation, and dissemination.

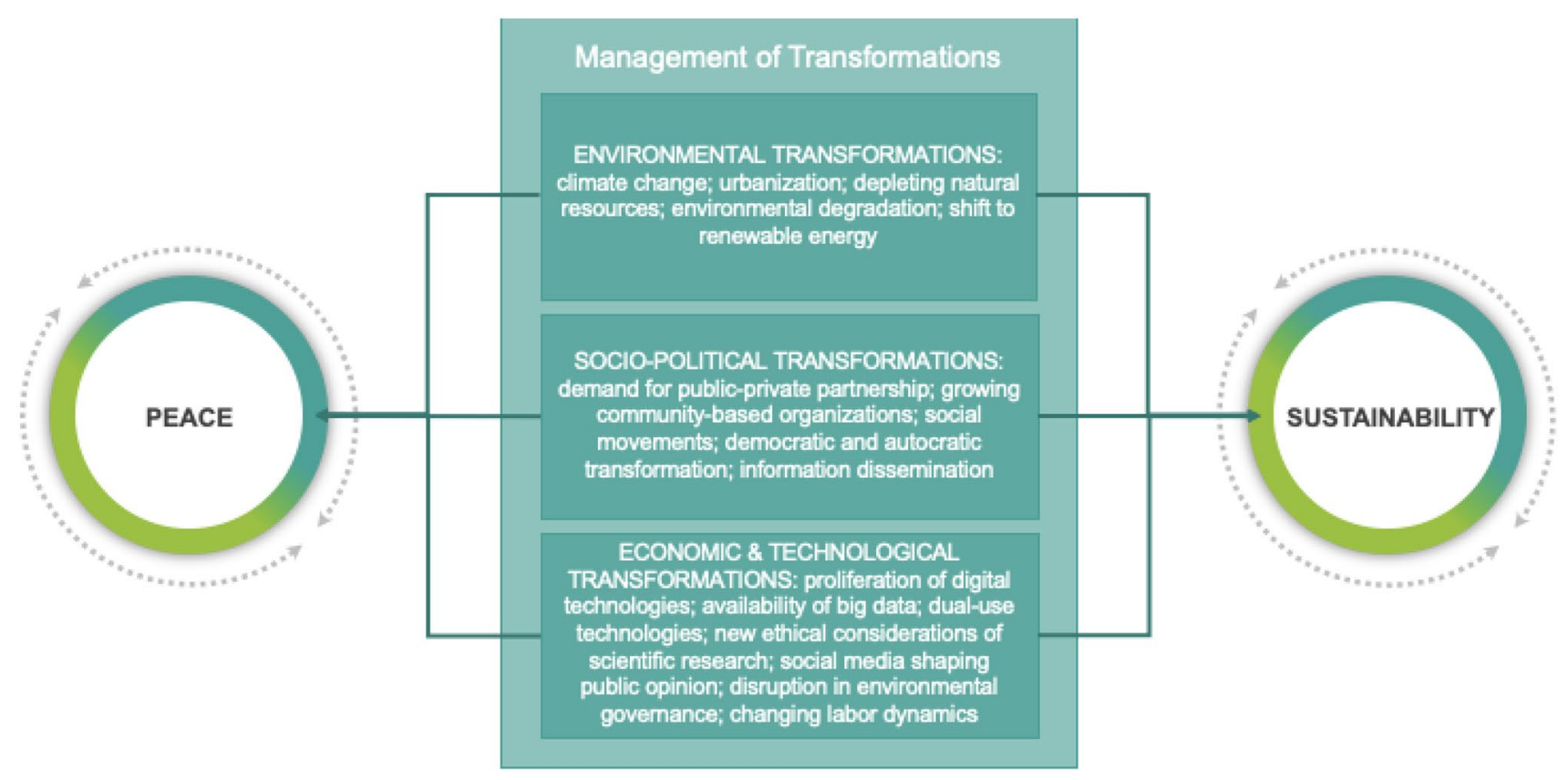

Fig. 4 Co-designed heuristic guide for investigating the peace-sustainability nexus 
One topic that is broad enough in scope to generate transdisciplinary research design and participation and can be considered when examining the management of transformations is migration. Contrary to what is often implied in contemporary political debates, migration and mobility are not in themselves aberrations or "problems to be solved" but rather an ordinary component of social condition throughout human history. This does not entail denying the tensions, conflicts, suffering, and diverging views surrounding mobility, but it does mean de-pathologizing (and de-mystifying) migration. The management of human migration, as an ordinary product of extraordinary transformation, will ultimately shape the potentialities for social conflict or cooperation and human suffering or enhancement. Translated into practice, and in the context of this article, such a recasting of mobility means that the potential of migration to enhance peace and sustainability - or worsen existing situations and various forms of conflict-depends on the conditions in which mobility takes place and is determined by a complex set of contextual variables.

A series of transformations in the global political economy, infrastructure, and environmental conditions has led to profound changes in migration patterns and displacement, and current policies struggle to keep pace with such changes. Internationally coordinated efforts to facilitate labor migration-not least regionally, which is the scale on which the majority of movement happens-can potentially help amplify the positive effects of mobility and reduce frictions. However, as witnessed by existing labour mobility schemes, such policies should be designed carefully (e.g., Clemens 2010; Nuti 2018). The risk is that, by conditioning policies on human and economic capital (e.g., schemes granting access to circular labor migration), the vulnerable and poor are not allowed to move, which can lead to a worsening of their conditions. On top of these measures, attention should also be directed toward cultural processes and integration. Of particular importance is civic education to foster integration and positive attitude to migration (such as a demystification of its impacts), as well as more considerate discussion by media (Esses et al. 2013; Kaur et al. 2016). On the one hand, the implementation of policies to ensure the rights of (im)migrants in relation to housing and employment, among other things, is vital to facilitate integration. In the absence of such measures, restrictive migration/refugee integration policies may lead to the seclusion of migrants and create sectoral division, which, in turn, can fuel the sentiments of fear on which anti-migration political rhetoric and xenophobic tendencies have thrived in recent years. On the other hand, it is also important to address the cause of migration/ refugee issues, as well as to analyze the responsibility of governments of origin.

In addition to migration, future research projects must be situated within broader contexts across several issues in order to examine the complex interactions of environmental, socio-political, and economic and technological considerations. Such research projects can shape and influence the existing discourse on peace and sustainability by anchoring on critical analyses of the historical evolution of peace, conflict, peacebuilding, conflict resolution, sustainability, and environmental degradation. They can be within the ambit of underexamined topics, such as those related to the Belt and Road Initiative, urbanization, transboundary resources, and cybersecurity. By nature of their complexity, these overarching themes enable researchers and practitioners to design transdisciplinary and long-term research projects with inclusive, participatory methodologies that can inform evidencebased decision-making.

\section{Conclusion}

This article scopes the peace-sustainability nexus by deliberating the characteristics of their complex and multifaceted relationship during a workshop participated by experts from relevant sectors and disciplines. Drawing on the workshop discussions, we have presented a co-designed heuristic guide for exploring the implications of various components of environmental, socio-political, and economic and technological transformations for the peace-sustainability nexus. The list of knowledge and knowledge gaps related to these thematic areas is non-exhaustive, but we have made a case for transdisciplinary and participatory research initiatives to enrich our understanding of the nexus. For instance, notable gaps in the participants' collective knowledge and disciplinary expertise were identified, namely the need to bring in psychologists and experts on psycho-social support and cultural expertise, specifically, academics who can challenge preconceived ideas about what a peaceful and sustainable society is and its inherent qualities. Our proposed guide aims to assist future academic and policy research in identifying the specific pathways through which peace and sustainability interact amid global transformations.

Peace and sustainability are elusive concepts and ideals. Peace can be either a force for change or a force for good. If conflict in terms of disputes about resource allocations and desired outcomes is understood to be inherent in any transformation, then it may be that conflict is part of the process of achieving more sustainable societies, particularly where pathways toward sustainability require a change in resource distribution. The specific nature of peace processes could shape and determine the potential for sustainability, in which inclusion, equity, and equality are prerequisites. Likewise, sustainability initiatives may reinforce existing conflicts and undermine stability or peacefulness, especially in societies that will experience a high degree of transformation. These scenarios, however, will ultimately depend on 
the governance and management of environmental, sociopolitical, and economic and technological transformations when addressing complex challenges in the context of global change.

Author contributions All authors contributed to the material preparation, data collection, and analysis. Specifically, the initial reports were written by (in alphabetical order) $\mathrm{CH}, \mathrm{MI}, \mathrm{YM}, \mathrm{RM}, \mathrm{PP}, \mathrm{KP}, \mathrm{AS}$, and DS. The methodology was designed by $\mathrm{HV}$ and SK, with the assistance of AS and DS. The first draft of the manuscript was written by DS, the revisions were led by DS and HV, and all authors commented on all versions of the manuscript. All authors read and approved the final manuscript.

\section{References}

Aklin M (2018) How robust is the renewable energy industry to political shocks? Evidence from the 2016 U.S. elections. Bus Polit 20(4):523-552. https://doi.org/10.1017/bap.2018.1

Anderson K, Ryan B, Sonntag W, Kavvada A, Friedl L (2017) Earth observation in service of the 2030 Agenda for Sustainable Development. Geo Spat Inf Sci 20(2):77-96. https://doi.org/10.1080/ 10095020.2017 .1333230

Aradau C, Blanke T (2017) Politics of prediction: security and the time/ space of governmentality in the age of big data. Eur J Soc Theory 20(3):373-391. https://doi.org/10.1177/1368431016667623

Arts K, van der Wal R, Adams WM (2015) Digital technology and the conservation of nature. Ambio 44:661-673. https://doi.org/ $10.1007 / \mathrm{s} 13280-015-0705-1$

Barnett J (2001) The meaning of environmental security: ecological politics and policy in the new security era. Zed Books, London

Baum MA, Potter PBK (2008) The relationships between mass media, public opinion, and foreign policy: toward a theoretical synthesis. Annu Rev Polit Sci 11(1):39-65. https://doi.org/10.1146/annurev. polisci.11.060406.214132

Bettini G, Gioli G, Felli R (2020) Clouded skies: how digital technologies could reshape "Loss and Damage" from climate change. Wires Clim Change 11(4):1-22. https://doi.org/10.1002/wcc.650

Born C, Eklöw K, Mobjörk M (2019) Advancing United Nations responses to climate-related security risks. SIPRI policy brief. Stockholm International Peace Research Institute, Stockholm

Brock L (1991) Peace through parks: the environment on the peace research agenda. J Peace Res 28(4):407-423. https://doi.org/10. $1177 / 0022343391028004006$

Brown J, Isaacs D (2005) The World Café: shaping our futures through conversations that matter. Berrett-Koehler Publishers, San Francisco

Chakrabarty D (2012) Postcolonial studies and the challenge of climate change. New Lit Hist 43(1):1-18. https://doi.org/10.1353/ nlh.2012.0007

Cheung G, Davies PJ (2017) In the transformation of energy systems: what is holding Australia back? Energy Policy 109:96-108. https://doi.org/10.1016/j.enpol.2017.06.056

Clemens MA (2010) A labor mobility agenda for development. Center for Global Development Working Paper No. 201. https://doi.org/ $10.2139 /$ ssrn. 1543396

Conca K, Dabelko GD (2002) Environmental peacemaking. Woodrow Wilson Center Press, Washington, DC

Crutzen PJ, Stoermer EF (2000) The Anthropocene. IGBP Newsletter $41: 17-18$
Cullis-Suzuki S, Pauly D (2010) Failing the high seas: a global evaluation of regional fisheries management organizations. Mar Policy 34(5):1036-1042. https://doi.org/10.1016/j.marpol.2010. 03.002

Dalby S (2002) Environmental security. University of Minnesota Press, Minneapolis

del Rio JS, Moctezuma D, Conde C, de Diego IM, Cabello E (2016) Automated border control e-gates and facial recognition systems. Comput Secur 62:49-72. https://doi.org/10.1016/j.cose.2016.07. 001

Dresse A, Fischhendler I, Nielsen JO, Zikos D (2018) Environmental peacebuilding: towards a theoretical framework. Coop Confl 54(1):99-119. https://doi.org/10.1177/0010836718808331

Esses VM, Medianu S, Lawson AS (2013) Uncertainty, threat, and the role of media in promoting the dehumanization of immigrants and refugees. J Soc Issues 69(3):518-536. https://doi.org/10.1111/ josi. 12027

Fisher J, Rucki K (2017) Re-conceptualizing the science of sustainability: a dynamical systems approach to understanding the nexus of conflict, development and the environment. Sustain Dev 25(4):267-275. https://doi.org/10.1002/sd.1656

Hegre H, Buhaug H, Calvin KV, Nordkvelle J, Waldhoff ST, Gilmore E (2016) Forecasting civil conflict along the shared socioeconomic pathways. Environ Res Lett 11(5):054002. https://doi.org/ 10.1088/1748-9326/11/5/054002

Hollyer JR, Rosendorff BP, Vreeland JR (2011) Democracy and transparency. J Polit 73(4):1191-1205. https://doi.org/10.1017/s0022 381611000880

Hønneland G (2004) Fish discourse: Russia, Norway, and the Northeast Arctic cod. Hum Org 63(1):68-77. https://doi.org/10.17730/ humo.63.1.qffrghak62dkh98b

Ide T (2020) The dark side of environmental peacebuilding. World Dev 127:104777. https://doi.org/10.1016/j.worlddev.2019.104777

Institute for Economics \& Peace (2018) Positive peace report 2018: analysing the factors that sustain peace. Sydney. http://visionofhu manity.org/reports

Jackson T, Curry J (2004) Peace in the woods: sustainability and the democratization of land use planning and resource management on crown lands in British Columbia. Int Plan Stud 9(1):27-42. https://doi.org/10.1080/1356347042000234961

Karekezi S (2002) Renewables in Africa-meeting the energy needs of the poor. Energy Policy 30:1059-1069. https://doi.org/10.1016/ S0301-4215(02)00058-7

Kaur S, Tan N, Dutta MH (2016) Media, migration and politics: the coverage of the Little India riot in The Straits Times in Singapore. J Creat Commun 11(1):27-43. https://doi.org/10.1177/09732 58616630214

Koomey JG, Matthews HS, Williams E (2013) Smart everything: will intelligent systems reduce resource use? Annu Rev Environ Resour 38(1):311-343. https://doi.org/10.1146/annurev-envir on-021512-110549

Kosmerlj M, Fladsrud T, Hjelmås E, Snekkenes E (2006) Face recognition issues in a border control environment. In: Zhang D, Jain AK (eds) Advances in biometrics. ICB 2006. Lecture notes in computer science. Springer, Berlin

Koubi V (2019) Climate change and conflict. Annu Rev Polit Sci 22:343-360. https://doi.org/10.1146/annurev-polis ci-050317-070830

Krampe F (2017) Toward sustainable peace: a new research agenda for post-conflict natural resource management. Glob Environ Politics 17(4):1-8

Krampe F (2019) Climate change, peacebuilding and sustaining peace. SIPRI policy brief. Stockholm International Peace Research Institute, Stockholm

Kyrou CN (2007) Peace ecology: an emerging paradigm in peace studies. Int J Peace Stud 12(1):73-92 
Lu M, Chen Z (2006) Urbanization, urban-biased policies, and urbanrural inequality in China, 1987-2001. Chin Econ 39(3):42-63. https://doi.org/10.2753/CES1097-1475390304

Mach KJ, Kraan CM, Adger WN, Buhaug H, Burke M, Fearon JD et al (2019) Climate as a risk factor for armed conflict. Nature 571(7764):193-197. https://doi.org/10.1038/s41586-019-1300-6

Mathews JT (1989) Redefining security. Foreign Aff. https://www.forei gnaffairs.com/articles/1989-03-01/redefining-security

McDonald M (2018) Climate change and security: towards ecological security? Int Theory 10(2):153-180. https://doi.org/10.1017/ S1752971918000039

Morita K, Okitasari M, Masuda H (2020) Analysis of national and local governance systems to achieve the sustainable development goals: case studies of Japan and Indonesia. Sustain Sci 15:179-202. https://doi.org/10.1007/s11625-019-00739-z

Myers N (1989) Environment and security. Foreign Policy 74:23-41. https://doi.org/10.2307/1148850

Nuti A (2018) Temporary labor migration with the EU as structural injustice. Ethics Int Aff 32(2):203-225. https://doi.org/10.1017/ S089267941800031X

Okitasari M, Sunam R, Mishra R, Masuda H, Morita K, Takemoto $\mathrm{K}$ et al (2019) Governance and national implementation of the 2030 Agenda: lessons from Voluntary National Reviews. UNUIAS Policy Brief 18. https://www.ias.unu.edu

Parsons RJ (2011) Strengthening sovereignty: security and sustainability in an era of climate change. Sustainability 3(9):1416-1451. https://doi.org/10.3390/su3091416

Peters K (2019) Disaster risk reduction in conflict contexts: an agenda for action. Overseas Development Institute, London

Pomeroy R, Parks J, Pollnac R, Campson T, Genio E, Marlessy C et al (2007) Fish wars: conflict and collaboration in fisheries management in Southeast Asia. Mar Policy 31(6):645-656. https://doi. org/10.1016/j.marpol.2007.03.012

Roberts A (2010) A great and revolutionary law? The first four years of India's Right to Information Act. Pub Adm Rev 70(6):925-933. https://doi.org/10.1111/j.1540-6210.2010.02224.x

Sharifi A, Simangan D, Kaneko S (2021) The literature landscape on peace-sustainability nexus: a scientometric analysis. Ambio 50:661-678. https://doi.org/10.1007/s13280-020-01388-8

Sharma E, Zhaoli Y, Sharma B (2007) ICIMOD's regional rangeland program for the Hindu Kush-Himalayas. Mt Res Dev 27(2):174-177

Shiroishi Y, Uchiyama K, Suzuki N (2018) Society 50: for human security and well-being. Computer 51(7):91-95. https://doi.org/ 10.1109/MC.2018.3011041

Shrivastava P, Suazo AE (2017) Peaceful sustainability. Bus Peace Sustain Dev 2017(10):28-34

Shue H (2014) Climate justice: vulnerability and protection. Oxford University Press, Oxford
Simangan D (2020) Where is the Anthropocene? IR in a new geological epoch. Int Aff 96(1):211-224. https://doi.org/10.1093/ia/iiz248

Solà-Martín A (2009) Is peacebuilding sustainable in Sierra Leone? Glob Change Peace Secur 21(3):291-307. https://doi.org/10.1080/ 14781150903168994

Solomon N, Birhane E, Gordon C, Haile M, Taheri F, Azadi H, Scheffran J (2018) Environmental impacts and causes of conflict in the Horn of Africa: a review. Earth Sci Rev 177:284-290. https://doi. org/10.1016/j.earscirev.2017.11.016

Srnicek N (2017) Platform capitalism. Polity Press, Cambridge

Surie MD (2011) Right to information in India: an effective tool to tackle corruption. The Asia Foundation, September 29. https:// asiafoundation.org/2011/09/28/right-to-information-in-india-aneffective-tool-to-tackle-corruption/

UN (1992) Rio declaration on environment and development. UN Doc. A/CONF.151/26 (vol I), 31 ILM 874. August 12

UN (2015) Transforming our world: the 2030 agenda for sustainable development. United Nations. UN Doc. A/RES/70/1. https://www. un.org/ga/search/view_doc.asp?symbol=A/RES/70/1\&Lang $=\mathrm{E}$

UN (2020) COVID-19 'profoundly affecting peace across the globe', says Secretary-General, in address to Security Council. UN Doc SC/14241. July 2, 2020. https://www.un.org/press/en/2020/sc142 41.doc.htm

van der Velden M (2018) Digitalisation and the UN sustainable development goals: what role for design. Interaction Design Arch J $37: 160-174$

Verweij M, Thompson M (2006) Clumsy solutions for a complex world: governance, politics and plural perceptions. Palgrave Macmillan, Basingstoke

Virji H, Sharifi A, Kaneko S, Simangan D (2019) The sustainabilitypeace nexus in the context of global change. Sustain Sci 14:14671468. https://doi.org/10.1007/s11625-019-00737-1

Zalasiewicz J, Waters CN, Williams M, Barnosky AD, Cearreta A, Crutzen P, Oreskes N (2015) When did the Anthropocene begin? A mid-twentieth century boundary level is stratigraphically optimal. Quat Int 383:196-203. https://doi.org/10.1016/j.quaint.2014. 11.045

Zuber R (2016) There can be no sustainable development without peace and no peace without sustainable development. In: Adams B, Bissio R, Ling CY, Judd K, Martens J, Obenland W (eds) Spotlight on sustainable development 2016: report of the reflection group on the 2030 Agenda for Sustainable Development, pp 115-121. https://www.2030spotlight.org/en/book/605/downloads

Publisher's Note Springer Nature remains neutral with regard to jurisdictional claims in published maps and institutional affiliations. 